\title{
Biotic interactions among estuarine infaunal opportunistic species
}

\author{
Robert B. Whitlatch and Roman N. Zajac \\ Department of Marine Sciences, The University of Connecticut, Marine Sciences Institute, Avery Point, Groton, \\ Connecticut 06340, USA
}

\begin{abstract}
Biotic interactions among soft-sediment infauna were investigated in a small New England estuary in order to determine what effect(s) established opportunistic species had on subsequent recolonization. Interactions were defined according to successional models developed by Connell and Slatyer (1977), e.g. facilitation, tolerance and inhibition. Adults of the opportunistic polychaetes Streblospio benedicti, Polydora ligni and Hobsonia florida were added at 2 densities to separate cores containing defaunated sediment. These cores and control cores containing no worms were sampled at $10 \mathrm{~d}$ intervals for $40 \mathrm{~d}$. Cores containing capillary tubes to simulate polychaete tubes were also deployed and sampled at $10 \mathrm{~d}$ intervals. Subsequent infaunal colonization densities of the polychaetes seeded to the cores - and also Capitella capitata, the amphipods Corophium insidiosum and Microdeutopus gryllotalpa and the anthozoan Nematostella vectensis - were analyzed for differences in recolonization with respect to the initial density of each of the established species. While more than 1 particular type of interspecific interaction operated during the study, the results indicate that the species could be divided into 2 groups, the polychaete and non-polychaete fauna. A predominance of inhibitory interactions (recolonization densities were significantly lower in cores with established species than in control cores) occurred among the polychaete fauna of the estuary. Some evidence of interspecific facilitation was found during initial sampling periods when overall densities of organisms were low. The effect of initial worm density on settlement inhibition was variable. The non-polychaete fauna appeared not to have been either positively or negatively affected by established species, thus suggesting some form of tolerance interaction or the lack of interaction. Cores containing simulated polychaete tubes generally had no effect on recolonization. Inhibitory interactions among opportunistic polychaetes may be due to intraspecific gregarious settlement and subsequent preemption of food and space resources. While biotic interactions among opportunistic species may play an important role in controlling successional dynamics, the specific type of interaction that occurs most likely depends on the species present, their density and habitat conditions. There appears to be no 'characteristic' type of biotic interaction which influences soft-bottom successional dynamics.
\end{abstract}

\section{INTRODUCTION}

Effects of disturbance and the following successional changes comprise a major portion of current research directed towards understanding marine benthic infaunal population and community dynamics (for reviews see Pearson and Rosenberg, 1978; Thistle, 1981; Rhoads and Boyer, 1982). These studies have been useful in providing insights into the nature and form of infaunal succession *, including its relation to the species life-history adaptations (Grassle and Grassle, 1974; McCall, 1977), modes of recolonization

\footnotetext{
- Succession is defined as a local progression of species invasion and occupancy following a disturbance (sensu Paine and Levin, 1981)
}

(Santos and Simon, 1980a), feeding types (Rhoads et al., 1978), taxonomic sequences (Simon and Dauer. 1977) and sedimentological changes (Rhoads and Boyer, 1982). Although we now have a reasonably good understanding of how marine infaunal community development proceeds following natural and experimentally-induced disturbances, patterns of faunistic change only suggest which abiotic and biotic mechanisms may be responsible for that change. The relative importance of biotic versus abiotic effects is not well known at present. It is also not clear whether successional sequences are dependent upon biological interactions between species or simply result from differential responses of species (or groups of species) to disturbed habitats under varying, prevailing abiotic conditions (Zajac and Whitlatch, 1982b) 
A general trend that emerges from many studies of infaunal succession is that there are certain species, usually termed opportunists, which are the first to respond to disturbance and dominate the initial stages of succession. Their ability to respond quickly to disturbance and attain high densities has been primarily attributed to their life-history features (e.g. wide dispersal ability, tolerance to disturbed conditions, high reproductive rates). Further, in many cases only 1 or 2 opportunistic species have been found to dominate the early phases of succession (e.g. Grassle and Grassle, 1974; Dauer and Simon, 1976; McCall, 1977; Arntz and Rumohr, 1982; Zajac and Whitlatch, 1982a). There are a number of alternative, though not mutually exclusive, explanations for the trend towards single species domination including temporal differences in the production and supply of larvae, differential settlement success within the disturbed site due to abiotic conditions and biotic interactions during settlement. Temporal variations in recruitment are known to occur both within and between seasons (Santos and Simon, 1980b; Arntz and Rumohr, 1982; Zajac and Whitlatch, 1982a) and can deternine which species initially colonize disturbed areas. However, coincident peaks in population growth, and presumably larval supply, of opportunists within the same habitat occur regularly (e.g. Boesch, 1973; Santos and Simon, 1974; Watling, 1975; McCall, 1978; Cammen, 1979; Santos and Simon, 1980a; Zajac and Whitlatch, 1982a), suggesting equal probabilities of response to disturbance. In addition, many infaunal opportunists are known to respond to a variety of disturbances (e.g. storms, red-tide induced mortality, organic pollution, oil spills, experimental defaunation). Therefore, the eurytolerance of opportunists does not necessarily support the contention that differences in tolerances to disturbed habitats generate the observed trend of domination by one or a few species

We hypothesize that patterns of single species dominance and changes in the composition of infaunal opportunists can result from biotic interactions between already settled species and other opportunistic species recruiting into a disturbed site. Here we present results from several field experiments to test this hypothesis and examine the extent and type of biotic interaction that may occur during the initial stages of recolonization in a temperate, estuarine, softbottom community.

There are several types of biotic interactions which may occur between infauna during recolonization. As previously suggested (Zajac and Whitlatch, 1982b), we have adopted as a theoretical framework for this study Connell and Slatyer's (1977) synthesis of how different biological mechanisms may influence successional change in natural communities. Their formulations are useful in defining processes responsible for the recolonization of disturbed sites. The 3 successional models are characterized by a predominant interspecific interaction:

(1) Facilitation - each species (or successional suite of species) which colonizes disturbed habitats makes the habitat less favorable for its own persistence and more favorable for their successors to invade and persist.

(2) Tolerance - early colonists have little effect on recruitment and population growth rates of later colonists. However, once established the more tolerant later colonists can inhibit re-invasion of the habitat by other species

(3) Inhibition - early colonists resist invasion through habitat modification or biological interactions (e.g. alleleopathy, interspecific competition) and persist until they either destroy their habitat or until they are disturbed.

All 3 successional models have either explicitly or implicitly been used to identify biotic processes affecting successional change in soft-bottom habitats, e.g. inhibition via adult-larval (Woodin, 1976; Richter and Sarnthein, 1977) or adult-adult (Levinton and Stewart, 1982) interactions; facilitation through biologicallymediated alteration of sediment fabric (Mills, 1967), chemistry and microbiota (Rhoads et al., 1978), or small-scale environmental alterations due to tubebuilding or feeding activities of deposit-feeders (Gallagher et al., 1983); tolerance generated by differences in the competitive abilities of early and later successional groups of species (Grassle and Grassle, 1974; McCall, 1977). Though the Connell-Slayter (1977) models apply to succession as a whole, from initial recolonization to climax conditions, our focus is on interactions between opportunistic species. We feel the models are general enough to be applicable to both within and between successional stage dynamics since early colonizing species may facilitate, inhibit or tolerate the settlement of other similarly adapted species, as well as species typical of later successional stages.

\section{STUDY STTE}

This study was conducted in Alewife Cove $\left(72^{\circ} 07^{\prime} \mathrm{W}, 41^{\circ} 21^{\prime} \mathrm{N}\right)$, a small (17 ha) estuary located in southeastern Connecticut, USA. The experiment was located in the upper basin of the cove (Zajac and Whitlatch, 1982a), adjacent to a small Spartina-dominated salt marsh. Physical, chemical and biological characteristics of Alewife Cove have previously been described by Welsh et al. (1978); Herring (1978); Welsh and Whitlatch (1980) and Zajac and Whitlatch (1982a, b), and only features relevant to the present study will be discussed. 
This study site is characterized by relatively large fluctuations in salinity (Welsh et al., 1978) and sedimentation (Welsh and Whitlatch, 1980). Water flow is primarily due to tidal action and rarely exceeds 1 to $2 \mathrm{~cm} \mathrm{~s}^{-1}$ (own obs.). The highly organic (20\% ashfree dry weight) sediments are composed of finegrained silts and clays ( $80 \%$ by weight). Numerically dominant infaunal species inhabiting the area include the polychaetes Streblospio benedicti, Polydora ligni, Hobsonia florida and Capitella capitata (Type I sibling species [sensu Grassle and Grassle, 1977], JP Grassle, in verbis), all previously characterized as opportunistic species (Pearson and Rosenberg, 1978). Seasonally abundant species found primarily in spring and summer include the amphipods Microdeutopus gryllotalpa and Corophium insidiosum. Earlier studies have shown that these 6 species dominated both early and late stages of succession following controlled disturbance manipulations although their recolonization patterns were seasonally variable (Zajac and Whitlatch, $1982 \mathrm{a}, \mathrm{b})$

\section{MATERLALS AND METHODS}

Field experiments were designed to assess what influence established populations of 3 species of tubiculous surface-feeding polychaetes (Streblospio benedicti, Hobsonia florida, Polydora ligni) had on the recruitment patterns of other benthic taxa. With reference to the 3 Connell-Slatyer (1977) models, inhibition was defined to occur if the abundance of subsequent colonists was reduced relative to samples initially containing no polychaetes; facilitation if the abundance of subsequent colonists were increased; and tolerance if the established polychaetes had little or no effect on subsequent recruitment patterns.

Experimental cores were prepared by defaunating sediments collected near the study site by air exposure for approximately $1 \mathrm{wk}$. Prior to air exposure, the sediments were pushed through a $2 \mathrm{~mm}$ sieve to remove large debris (e.g. rocks, twigs, leaves). Plastic cores ( $5 \mathrm{~cm}$ diameter, $10 \mathrm{~cm}$ deep, bottoms covered by $1 \mathrm{~mm}$ mesh plastic screening) were then filled to the top with defaunated sediment and submerged in a filtered, circulating seawater table for several days.

Individuals of each species used in the experiment were collected from Alewife Cove and sorted from residues remaining on a $1 \mathrm{~mm}$ mesh sieve. Individuals of one species of polychaete were then added to the cores at a particular density. Densities used were 15 and 30, 10 and 20, and 4 and 8 for Streblospio benedicti, Polydora ligni and Hobsonia florida, respectively (hereafter referred to as S1X, S2X, P1X, P2X, $\mathrm{H} 1 \mathrm{X}$ and $\mathrm{H} 2 \mathrm{X}$ treatments, respectively). These densities reflected recolonization and ambient density ranges of the 3 species in Alewife Cove based on an earlier study (Zajac and Whitlatch, 1982a). Cores were removed separately from the seawater table in a container filled with filtered seawater, and organisms were placed on the sediment surface of the core at densities indicated above. After the worms burrowed into the sediment and began constructing tubes, the core was placed back into the water table. After all cores $(5$ replicates of each density for each of 4 exposure periods, i.e. 120 cores) were filled with organisms (a $24 \mathrm{~h}$ period), each was capped underwater with a plastic cap which trapped a small volume of water ( $-30 \mathrm{ml}$ ) above the sediment surface, minimizing disturbance associated with transportation and deployment of the containers.

Prior to deployment, the cores containing established densities of polychaetes were placed in plastic buckets ( $20 \mathrm{~cm}$ height, $0.229 \mathrm{~m}^{2}$ surface area). For each species there were 4 buckets ( 1 for each sampling time), each containing 5 replicate cores of both species-specific densities. In addition, 40 cores containing defaunated sediments and no organisms were placed in 2 other buckets to serve as controls for the experiment. The buckets were prepared by placing $10 \mathrm{~cm}$ of sediment into the bottom of the bucket, adding the experimental cores, and then placing sediment into the spaces between the cores to avoid shifting within each bucket. The surface of the sediments in the experimental cores and the sediments surrounding the cores were flush with the top of the bucket, i.e. there was no 'dead space' created by the edge of the bucket which could prevent larvae produced by the manipulated species from swimming out of the bucket, or cause larvae passing over the buckets to become trapped.

The experiment was deployed on June 26, 1981. Working from a skiff, experimental buckets were placed into a frame $(1 \times 1.5 \mathrm{~m})$ constructed from PVC pipe containing 3 rows of 4 open bucket holders. Buckets containing control cores (and after Day 10 also short-term controls and tube controls, see below) were placed into a second frame adjacent to that containing experimental cores. The placement of the buckets was semi-random. The row into which a set of 4 buckets for each species was placed was randomized; however, the rows were sampled sequentially at each sampling period to reduce disturbance around the experimental array during sampling.

At $10 \mathrm{~d}$ intervals for $40 \mathrm{~d}$, samples $(5$ control cores and a bucket for each species containing 5 cores of $1 \mathrm{X}$ and 5 cores of $2 \mathrm{X}$ densities) were collected and transported to the laboratory where they were preserved whole in $10 \%$ buffered formalin containing rose bengal. After fixation, samples were sieved and transferred to $70 \%$ ETOH. To test which sieve sizes should be 
used, 4 randomly chosen cores from the second sampling period were sieved with nested 110,180, 212 and $300 \mu \mathrm{m}$ mesh screens and each fraction was sorted under a dissecting microscope. Less than $1 \%$ of the total fauna was retained on the $110 \mu \mathrm{m}$ fraction and subsequently all samples (including Day 10 samples) were screened with nested $180 \mu \mathrm{m}$ and $300 \mu \mathrm{m}$ mesh screens. Each sample fraction was sorted under a dissecting microscope (at $6.4 \mathrm{x}$ to $16 \mathrm{x}$ and $16 \mathrm{x}$ to $40 \mathrm{x}$, respectively) and species abundance data for each fraction was pooled. Approximately $96 \%$ of the total macrofauna found during the study were collected on the $300 \mu \mathrm{m}$ screen

In addition to the above design, 2 other treatments were deployed. Since pulses of larval settlement are known to vary temporally in the Cove (Zajac and Whitlatch, 1982a), one treatment (termed 'short-term controls') consisted of cores containing no animals which were used to estimate larval recruitment patterns between sampling dates (10 d periods). Also, since the presence of tubes constructed by infauna are known to influence settlement and survivorship of infauna (Eckman, 1979; Eckman et al., 1981; Woodin, 1981), another treatment (referred to as 'tube-controls') was deployed that consisted of cores containing 20 glass capillary tubes. These tubes $(3 \mathrm{~mm}$ diameter, $30 \mathrm{~mm}$ long) were pushed into the sediment until approximately $1 \mathrm{~mm}$ was exposed above the sediment surface. Five replicate cores of both short-term and tube-controls were deployed on each sampling date and were collected on the subsequent sampling date. These cores were prepared for deployment, sampled and processed in a manner identical to those described above for the species manipulations.

Individual densities of the numerically dominant species (see 'Results') were analyzed, each sampling date separately, using a 1-way analysis of variance (ANOVA) to test the hypothesis that there were no significant differences in species recruitment with respect to the density of each established species (e.g. Streblospio benedicti, Polydora ligni and Hobsonia florida). The starting density of manipulated species (see above) was subtracted from the total number found in each $1 \mathrm{X}$ and $2 \mathrm{X}$ species treatment core prior to analysis as a correction for recruitment estimates. To ascertain differences between individual treatment means (e.g. species density levels of the particular treatments), contrasts were used (SAS, 1982). Recruitment densities between short-term controls and tube controls were tested with 2-way ANOVAS. Abundances were $\log _{10}(x+1)$ transformed prior to analysis when data did not comply with the homoscedasticity assumption of ANOVA. A significance level of $\mathrm{p}<0.05$ was used for all statistical tests.

Our experimental design did not allow for testing within bucket variability which can potentially be a source of error in comparing species effects on recruitment. However, within bucket variability was tested for a similar experimental and deployment design by Zajac (1981) at several sites within Alewife Cove, including the one at which this experiment was conducted. Out of 54 comparisons of within bucket variability (in a fully randomized design) for total recolonization, only 4 yielded significant differences between replicate buckets, and none of these were at this study's experimental site (Zajac, 1981). Thus, we feel that within bucket variation in this experiment is low and does not constitute a major source of error in determining worm density effects on recruitment. Further, we feel that though the experimental cores were placed above the sediment-water interface, they do provide a good test of infaunal dynamics within surrounding ambient sediments. Our previous studies employing this type of experimental deployment (Zajac and Whitlatch, 1982a, b) showed that at many times population fluctuations within experimental buckets and ambient sediments were not significantly different.

\section{RESULTS}

During the course of the study, 23 species of macrofauna settled into the various cores. Seven species, comprising approximately $99 \%$ of all individuals encountered, were the polychaetes Streblospio benedicti, Hobsonia florida, Polydora ligni and Capitella capitata, the amphipods Microdeutopus gryllotalpa and Corophium insidiosum, and the anthozoan Nematostella vectensis. Table 1 summarizes relevant life-history features of these species.

\section{Species manipulation experiments}

Species composition in the various experimental treatment and control cores was quite similar; however, species-specific recruitment densities varied among treatments. These recruitment patterns are discussed for the seven most abundant species.

\section{Streblospio benedicti}

This polychaete was the most abundant colonizer (53.4\% of the total number of individuals settling) in the study and its densities peaked at Day 20 in all treatments, followed by a general decline in numbers during the remainder of the study (Fig. 1). Colonization of Streblospio benedicti differed significantly with respect to density at each sampling date in each of the 
Table 1. Life-history characteristics of the 7 most common macrofaunal taxa found during the study

\begin{tabular}{|c|c|c|}
\hline Taxon & Feeding/motility type & Reproductive features \\
\hline \multicolumn{3}{|l|}{ Polychaetes } \\
\hline Streblospio benedicti & $\begin{array}{l}\text { Bi-palpate; surface deposit-feeder; } \\
\text { tube-dwelling }\end{array}$ & $\begin{array}{l}\text { Larviparous: " planktonic } \\
\text { phase }-1 \text { to } 14 \mathrm{~d} \text {; } \\
\text { generation time }-30 \text { to } 50 \mathrm{~d}\end{array}$ \\
\hline Hobsonia florida & $\begin{array}{l}\text { Multi-tentaculate } \\
\text { surface deposit-feeder; } \\
\text { tube-dwelling }\end{array}$ & $\begin{array}{l}\text { Tube brooding: planktonic phase (?); } \\
\text { generation time } \sim 25 \text { to } 35 \mathrm{~d}\end{array}$ \\
\hline Polydora ligni & $\begin{array}{l}\text { Bi-palpate; surface deposit-feeder; } \\
\text { tube-dwelling }\end{array}$ & $\begin{array}{l}\text { Tube brooding; plankton phase } \sim 2 \\
\text { to } 10 \mathrm{~d} \text {; generation time }-30 \text { to } 40 \mathrm{~d}\end{array}$ \\
\hline $\begin{array}{l}\text { Capitella capitata } \\
\quad \text { (Type I) }\end{array}$ & Sub-surface deposit-feeder & $\begin{array}{l}\text { Tube brooding; plankton phase } \\
\text { several hours; generation } \\
\text { time } \sim 30 \text { to } 40 \mathrm{~d}\end{array}$ \\
\hline \multicolumn{3}{|l|}{ Amphipod crustaceans } \\
\hline Corophium insidiosum & $\begin{array}{l}\text { Surface deposit-feeder; } \\
\text { tube-dwelling }\end{array}$ & $\begin{array}{l}\text { Brooding; generation time } \\
\sim 30 \text { to } 90 \mathrm{~d}\end{array}$ \\
\hline Microdeutopus gryllotalpa & $\begin{array}{l}\text { Surface deposit/suspension-feeder; } \\
\text { tube-dwelling }\end{array}$ & $\begin{array}{l}\text { Brooding; generation time } \\
-30 \text { to } 50 \mathrm{~d}\end{array}$ \\
\hline \multicolumn{3}{|l|}{ Anthozoan } \\
\hline Nematostella vectensis & Infaunal; zooplanktivore (?) & $?$ \\
\hline
\end{tabular}

species manipulations (Table 2). Relative to control core densities, $S$, benedicti colonization into cores containing $S$. benedicti (S-cores) increased significantly between Days 10 and 30 (Table 3), thus these effects were classified as intra-specific facilitation. By Day 40 densities in S1X and S2X cores fell below control levels. In cores initially seeded with Hobsonia florida (H-cores), colonization of $S$. benedicti was significantly higher at Day 10 than in control cores, implying facilitation of $S$. benedicti recruitment by $H$. florida. Between Days 10 and 40, however, densities of $S$. benedicti in $\mathrm{H}$-cores were significantly lower than in control cores. The effects of $P$. ligni (P-cores) on $S$. benedicti were mixed; Day 10 recruitment was enhanced, Days 20 and 30 showed mixed differences. and Day $40 \mathrm{~S}$. benedicti densities were significantly
Fig. 1. Streblospio benedicti. Mean abundances in $\operatorname{S} 1 X(\Delta), \operatorname{S} 2 X(\Delta), \operatorname{P} 1 X(O)$, P2X (๑), H1X (口), H2X (ם), and control (O) cores; $\pm 1 \mathrm{SE}$

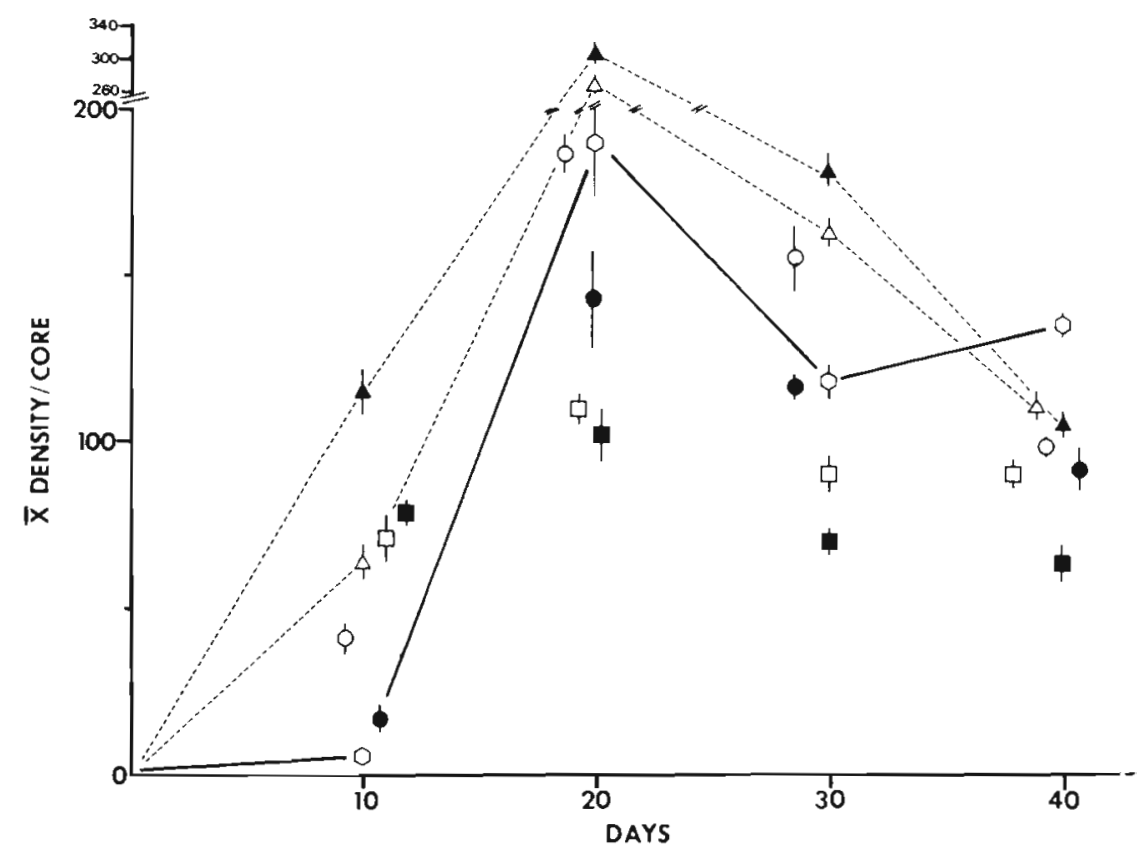


Table 2. Results of 1-way ANOVA, testing species density differences in each species specific treatment at 10, 20,30 and 40 d. In each case an analysis was based on 5 replicate cores of each treatment, (i.e. control and $1 \mathrm{X}$ and $2 \mathrm{X}$ densities of the species tested).

Thus, for each analysis there were 2 degrees of freedom for the model and 12 for the error. At each sampling date, the same 5 control cores were used for each species-specific analysis. Values are probabilities of exceeding generated F statistics

\begin{tabular}{|c|c|c|c|c|c|c|c|c|}
\hline Treatment & & $\begin{array}{c}\text { Streblospio } \\
\text { benedicti }\end{array}$ & $\begin{array}{l}\text { Hobsonia } \\
\text { florida }\end{array}$ & $\begin{array}{l}\text { Polydora } \\
\text { ligni }\end{array}$ & $\begin{array}{l}\text { Capitella } \\
\text { capitata }\end{array}$ & $\begin{array}{c}\text { Microdeutopus } \\
\text { grylltal. }\end{array}$ & $\begin{array}{l}\text { Corophium } \\
\text { insidiosum }\end{array}$ & $\begin{array}{c}\text { Nematostella } \\
\text { vectenis }\end{array}$ \\
\hline \multirow{4}{*}{$\begin{array}{l}\text { Streblospio } \\
\text { benedicti }\end{array}$} & D10 & .0001 & .2191 & .0577 & .0001 & 1138 & .0838 & 1.000 \\
\hline & D20 & .0001 & .0013 & .0001 & .0001 & .4326 & .7964 & .6670 \\
\hline & D30 & .0001 & .0002 & 4008 & .0001 & .0291 & .0573 & .9340 \\
\hline & D40 & .0002 & .0001 & .0013 & .0606 & .8438 & .3547 & .0036 \\
\hline \multirow{4}{*}{$\begin{array}{l}\text { Hobsonia } \\
\text { florida }\end{array}$} & D 10 & .0001 & .0531 & .0783 & .5360 & .6468 & .4046 & .0326 \\
\hline & $\mathrm{D} 20$ & .0001 & .0029 & .0002 & .0004 & .1803 & .4414 & .6543 \\
\hline & D30 & .0001 & .0032 & .1114 & .0004 & .0002 & 6688 & .4227 \\
\hline & D40 & .0001 & .0019 & .0188 & .0010 & .9440 & .5841 & .0627 \\
\hline \multirow{4}{*}{$\begin{array}{l}\text { Polydora } \\
\text { ligni }\end{array}$} & D10 & .0001 & .0001 & .0001 & .0001 & .0747 & .7156 & .0351 \\
\hline & D20 & .0239 & .0001 & .0001 & .0001 & .3784 & .3121 & .3777 \\
\hline & D30 & .0018 & .0001 & .0005 & .0002 & .1476 & .0014 & .4855 \\
\hline & $\mathrm{D} 40$ & .0001 & .0001 & .0001 & .0001 & .9707 & .5751 & 1031 \\
\hline
\end{tabular}

lower than in control cores. Differences in density of $S$. benedicti when the initial densities of manipulated species were doubled (Table 3) were also mixed.

\section{Hobsonia florida}

The highest densities of Hobsonia florida were generally seen between Days 10 and 20 in the 6 treatments, while control core densities remained relatively high from Day 10 to the termination of the experiment (Fig. 2). Significant differences in $H$. florida settlement were attributable to species manipulations in each case except at Day 10 in S-cores (Table 2). H. florida exhibited a mixed recruitment behavior into H-cores. Facilitation occurred during the first $20 \mathrm{~d}$ as recruitment was higher into its own cores compared to controls, but at Days 30 and 40, H. florida densities generally fell below the control core densities. Recruitment was higher in $\mathrm{H} 2 \mathrm{X}$ cores at Days 20,30 and 40. Inhibition of $H$. florida settlement occurred in S-cores and Pcores (Table 3). The effect of Polydora ligni on $H$. florida occurred throughout the study, while inhibition by Streblospio benedicti did not occur at Day 10, and S1X treatments at Day 20. Initial density of the manipulated species proved to be significant only in P-cores although the effect was mixed depending on sampling date (Table 3).

\section{Polydora ligni}

Polydora ligni abundance in experimental cores was generally highest at Day 20 followed by declining densities in all treatments except in P2X (Fig. 3). There were significant differences in $P$. ligni recruitment with respect to each of the manipulated species but not on each sampling date (Table 2). In most cases, P. ligni enhanced its own settlement during the study (Table 3) especially at Days 10 and 40, and Day 30 in P2X cores. At Day 20 when peak densities of $P$. ligni occurred, there were no significant differences between control and $2 \mathrm{X}$ cores while recruitment fell below control levels in the $1 \mathrm{X}$ cores. There were significant density effects at Days 20, 30 and 40, with higher levels of $P$. ligni being found in $2 \mathrm{X}$ than in $1 \mathrm{X}$ P-cores. Streblospio benedicti either had a negative effect (Days 20 and 40), or no effect (Day 30) on P. ligni recruitment (Table 3). Density of $P$. ligni in S1X cores at Day 10 was significantly higher than in control cores, and usually there were no differences between $1 \mathrm{X}$ and $2 \mathrm{X}$ S-cores (Table 3). Hobsonia florida showed inhibition of $P$. ligni recruitment in $\mathrm{H} 1 \mathrm{X}$ cores at Day 20 and in H2X cores at Day 40 , and facilitation in $\mathrm{H} 1 \mathrm{X}$ cores at Day 10 , but generally there were no significant differences between controls and $1 \mathrm{X}$ or $2 \mathrm{X}$ treatments.

\section{Capitella capitata}

Densities of Capitella capitata generally increased during the first $30 \mathrm{~d}$ of the study and declined by Day 40 (Fig. 4). Differences in C. capitata density between treatments were usually highly significant (Table 2). Although there was a similar temporal density trend of C. capitata in control and experimental cores, each of the manipulated species negatively affected colonization of C. capitata (Table 3). Densities of C. capitata in P-cores fell below control levels (except 1X, Day 40), and there were significantly negative density effects at each sampling date (e.g. densities in P1X cores were 
significantly greater than in P2X cores). S-cores also had a negative effect on $C$. capitata recruitment in most cases. In $\mathrm{H}$-cores there were no significant differences at Day 10, nor in $2 X$ cores at Day 30 . Collectively, the most pronounced inhibitory effects occurred at Days 20 and 30 (Table 3, Fig. 4).

\section{Microdeutopus gryllotalpa}

Densities of Microdeutopus gryllotalpa were quite variable in control and species manipulation cores during most of the study (Fig. 5). Densities generally increased through Day 40 but peaked in $\mathrm{H}$-cores at Day 30. There were few significant differences in abundance due to species treatment effects (Table 2), but facilitation occurred in S2X, and H1X and H2X cores at Day 30.

\section{Corophium insidiosum}

Colonization of Corophium insidiosum was comparatively low throughout the study and similar to that described for Microdeutopus gryllotalpa (Fig. 6). Densities of $C$. insidiosum reached highest levels by Day 30 in control, $\mathrm{H}$-cores and S-cores, and at Day 40 in control cores. Experimental differences were found only in S-cores and P-cores at Day 30 when recruitment was inhibited by each species (Table 3 ).

\section{Nematostella vectensis}

This anthozoan increased steadily in abundance throughout the study in all cores (Fig. 7). Recruitment was generally unaffected by the manipulated species.

Table 3. Summary of contrasts testing of the effect of species manipulations on recruitment abundances of Alewife Cove macrofauna. -: inhibition; + : facilitation; 0 : no significant effect $(p>0.05)$. Values under 'Density' column compare effects of initial species density treatments $(1 \mathrm{X}, 2 \mathrm{X}$ ) on recruitment (see 'Materials and Methods'). A value of 1 , for example, denotes that abundances in a $1 X$ treatment were significantly greater $(p<0,05)$ than the corresponding $2 X$ treatment, while 2 indicates that densities in $2 X$ treatments were significantly greater than $1 X$ treatments. NS: no significant differences between density treatments

\begin{tabular}{|c|c|c|c|c|c|c|c|c|c|c|}
\hline \multirow[t]{3}{*}{ Effects } & \multirow[b]{3}{*}{ Day } & \multicolumn{9}{|c|}{ Manipulations } \\
\hline & & \multicolumn{3}{|c|}{ Streblospio } & \multicolumn{3}{|c|}{ Hobsonia } & \multicolumn{3}{|c|}{ Polydora } \\
\hline & & $1 X$ & $2 \mathrm{X}$ & Density & $1 \mathrm{X}$ & $2 \mathrm{x}$ & Density & $1 \mathrm{X}$ & $2 \mathrm{X}$ & Density \\
\hline \multirow{4}{*}{$\begin{array}{l}\text { Streblospio } \\
\text { benedicti }\end{array}$} & 10 & + & + & 2 & + & + & NS & + & + & 1 \\
\hline & 20 & + & + & NS & - & - & NS & 0 & - & 1 \\
\hline & 30 & + & + & 2 & - & - & 1 & + & 0 & 1 \\
\hline & 40 & - & - & NS & - & - & 1 & - & - & NS \\
\hline \multirow{4}{*}{$\begin{array}{l}\text { Hobsonia } \\
\text { florida }\end{array}$} & 10 & 0 & 0 & NS & 0 & + & NS & - & - & 2 \\
\hline & 20 & 0 & - & 1 & + & + & 2 & - & - & 1 \\
\hline & 30 & - & - & NS & - & 0 & 2 & - & - & 1 \\
\hline & 40 & - & - & NS & - & 0 & 2 & - & - & 2 \\
\hline \multirow{4}{*}{$\begin{array}{l}\text { Polydora } \\
\text { ligni }\end{array}$} & 10 & + & 0 & 1 & + & 0 & 1 & + & + & NS \\
\hline & 20 & - & - & NS & - & 0 & 2 & - & 0 & 2 \\
\hline & 30 & 0 & 0 & NS & 0 & 0 & NS & 0 & + & 2 \\
\hline & 40 & - & - & NS & 0 & - & NS & + & + & 2 \\
\hline \multirow{4}{*}{$\begin{array}{l}\text { Capitella } \\
\text { capitata }\end{array}$} & 10 & 0 & - & 1 & 0 & 0 & NS & - & - & 1 \\
\hline & 20 & - & - & NS & - & - & 1 & - & - & 1 \\
\hline & 30 & - & - & 2 & - & 0 & 2 & - & - & 1 \\
\hline & 40 & 0 & - & NS & - & - & NS & 0 & - & 1 \\
\hline \multirow{4}{*}{$\begin{array}{l}\text { Microdeutopus } \\
\text { gryllotalpa }\end{array}$} & 10 & 0 & 0 & NS & 0 & 0 & NS & 0 & 0 & NS \\
\hline & 20 & 0 & 0 & NS & 0 & 0 & NS & 0 & 0 & NS \\
\hline & 30 & 0 & + & NS & + & + & NS & 0 & 0 & NS \\
\hline & 40 & 0 & 0 & NS & 0 & 0 & NS & 0 & 0 & NS \\
\hline \multirow{4}{*}{$\begin{array}{l}\text { Corophium } \\
\text { insidiosum }\end{array}$} & 10 & 0 & 0 & NS & 0 & 0 & NS & 0 & 0 & NS \\
\hline & 20 & 0 & 0 & NS & 0 & 0 & NS & 0 & 0 & NS \\
\hline & 30 & - & - & NS & 0 & 0 & NS & - & - & NS \\
\hline & 40 & 0 & 0 & NS & 0 & 0 & NS & 0 & 0 & NS \\
\hline \multirow{4}{*}{$\begin{array}{l}\text { Nematostella } \\
\text { vectensis }\end{array}$} & 10 & 0 & 0 & NS & + & + & NS & 0 & + & NS \\
\hline & 20 & 0 & 0 & NS & 0 & 0 & NS & 0 & 0 & NS \\
\hline & 30 & 0 & 0 & NS & 0 & 0 & NS & 0 & 0 & NS \\
\hline & 40 & + & + & NS & 0 & + & NS & 0 & 0 & NS \\
\hline
\end{tabular}




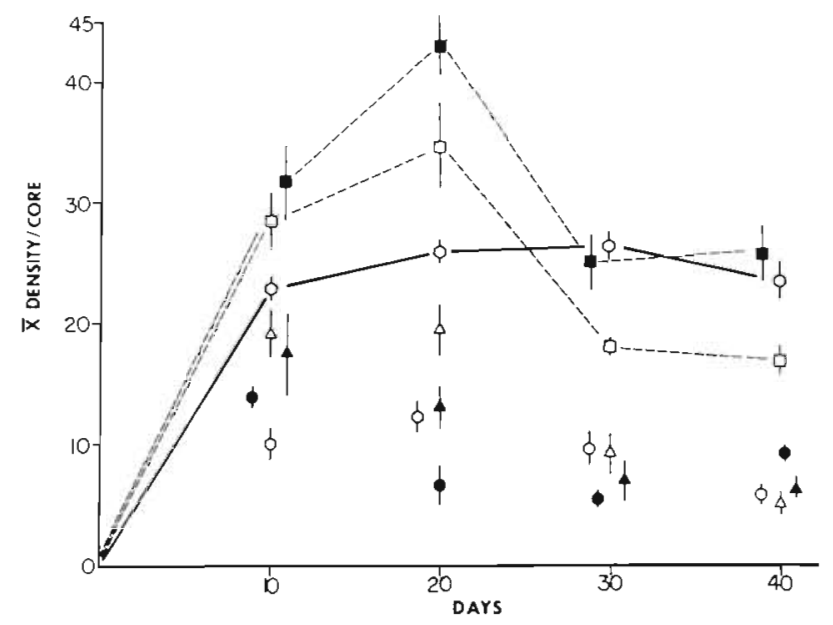

Fig. 2. Hobsonia florida. Mean abundances in the various treatment and control cores (see Fig. 1 legend for symbol designations)

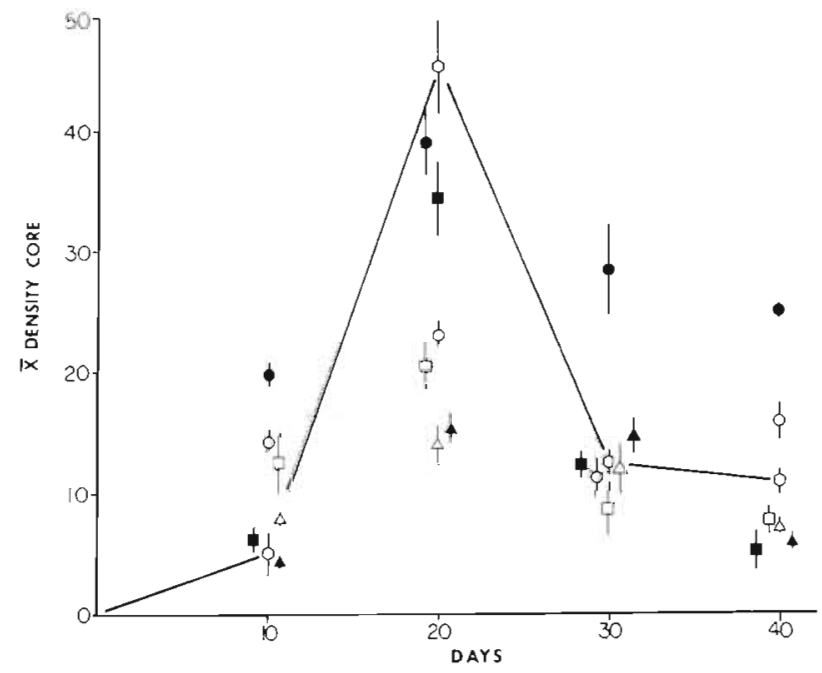

Fig. 3. Polydora ligni. Mean abundances in the various treatment and control cores (see Fig. 1 legend for symbol designations)

Significant core effects occurred in S-cores at Day 40 , and in $\mathrm{H}$-cores and P-cores at Day 10 (Table 2). In each. case, Nematostella vectensis recruitment was facilitated by the manipulated species (Table 3 ).

\section{Effects of simulated tubes on recruitment patterns}

Fig. 8 shows the response of the 7 most common species to the presence (tube controls) and absence (short-term controls) of simulated tubes. Two-way ANOVA tests (Time - [Days 20, 30, 40] vs core type [short-term controls, tube controls]) indicated that only Polydora ligni and Hobsonia florida showed overall significant core type effects $(\mathrm{F}=9.47, \mathrm{p}<.001 ; \mathrm{F}=$

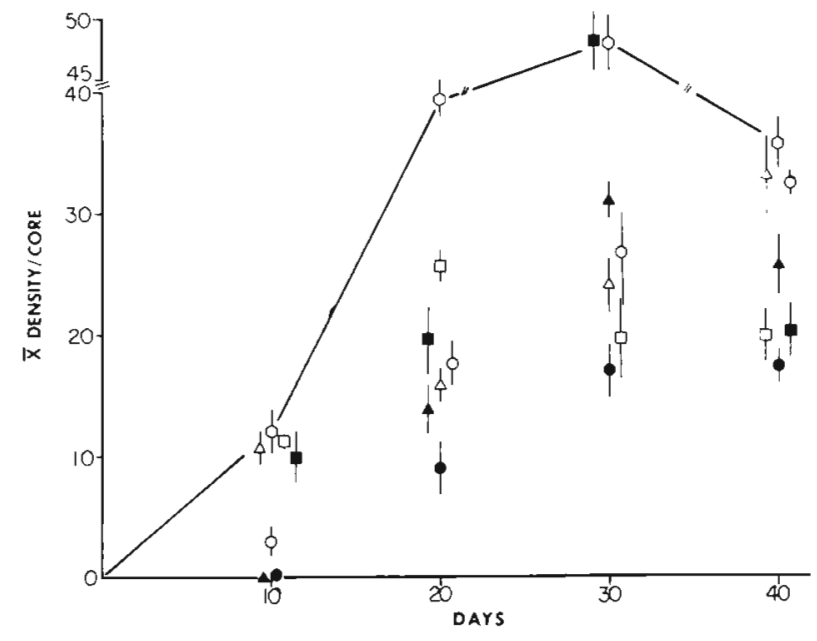

Fig. 4. Capitella capitata. Mean abundances in the various treatment and control cores (see Fig. 1 legend for symbol designations)

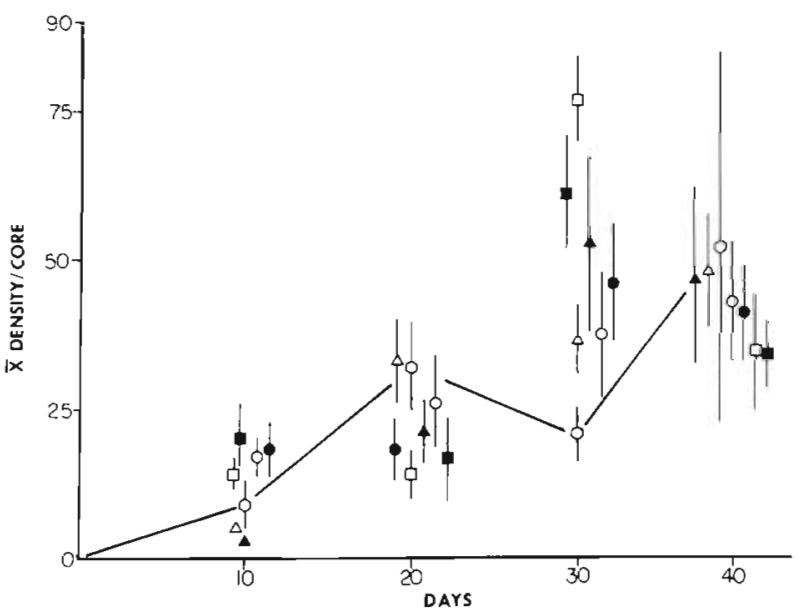

Fig. 5. Microdeutopus gryllotalpa. Mean abundances in the various treatment and control cores (see Fig. 1 legend for symbol designations)

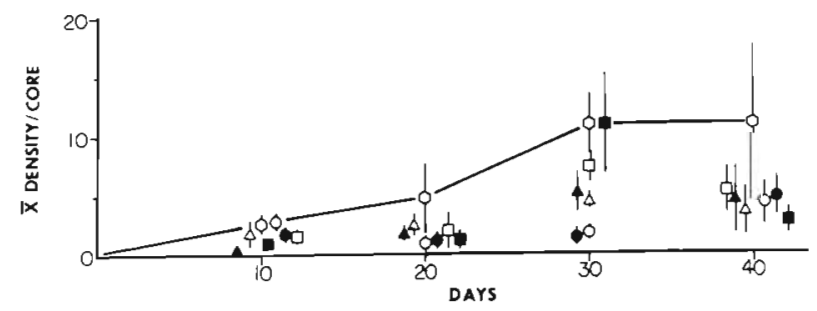

Fig. 6. Corophium insidiosum. Mean abundances in the various treatment and control cores (see Fig. 1 legend for symbol designations)

7.98, $\mathrm{p}<.01$ ). Using a priori contrast tests (using mean square [MS] error of the overall ANOVAs to test against MS contrasts) indicated significant density differences $(p<0.05)$ in recruitment between tube-controls and short-term control cores in 4 of 21 possible comparisons. In 3 cases, more larvae were associated 
with cores containing tubes, and in 1 case more recruits were found in cores without tubes (Fig. 8).

\section{DISCUSSION}

Patterns of interspecific interactions during the successional process were highly variable with respect to manipulated species and their initial densities (Table 3). However, while more than 1 particular type of interspecific interaction operated at the same time, Table 3 indicates that species fall into 2 groups. Inhibitory interactions, implied by negative signs in Table 3, appear to be predominant among the polychaetes of Alewife Cove. Interspecific facilitation, implied by positive signs in Table 3 , were generally found during the earlier phases of the experiment when abundances of polychaetes were relatively low (Fig. 1 to 7). As population abundances of the manipulated species increased, interspecific interactions tended to change signs (e.g. positive to negative), a pattern predicted if inhibitory interactions are influenced by a density-dependent mechanism. However, the effect of initial density on the intensity of settlement inhibition (Table 3) was variable and not always consistent with the prediction of a density-dependent process (i.e. $2 \mathrm{X}$ treatments having a greater negative effect on interspecific recruitment than $1 \mathrm{X}$ treatments). In order to examine adequately the importance of density-dependent biotic interactions on influencing infaunal successional dynamics, manipulations of species over much wider density ranges are needed (e.g. Wilson, 1983) and are currently underway (Whitlatch et al., in prep.). Tolerance (originally defined as no or little interaction among species) appears to have occurred primarily between the manipulated species

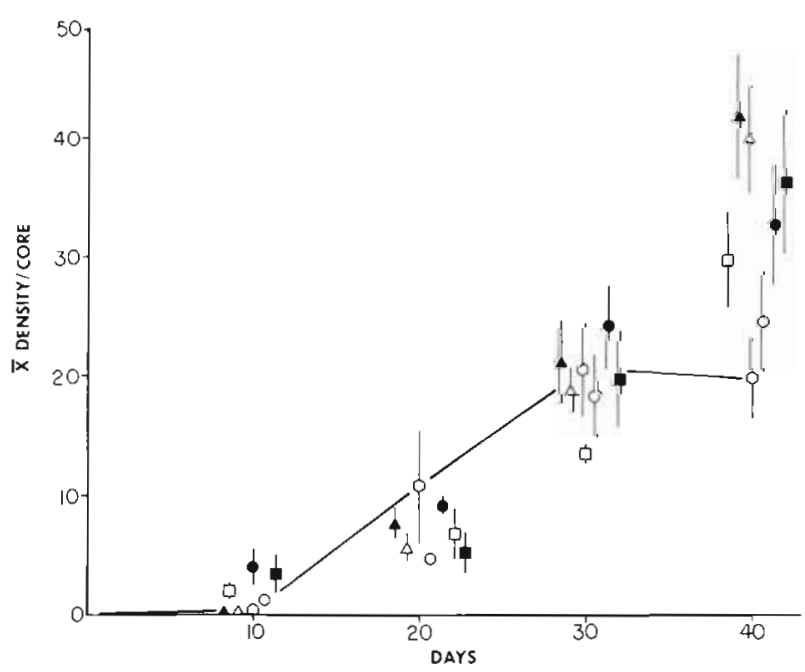

Fig. 7. Nematostella vectensis. Mean abundances in the various treatment and control cores (see Fig. 1 legend for symbol designations)
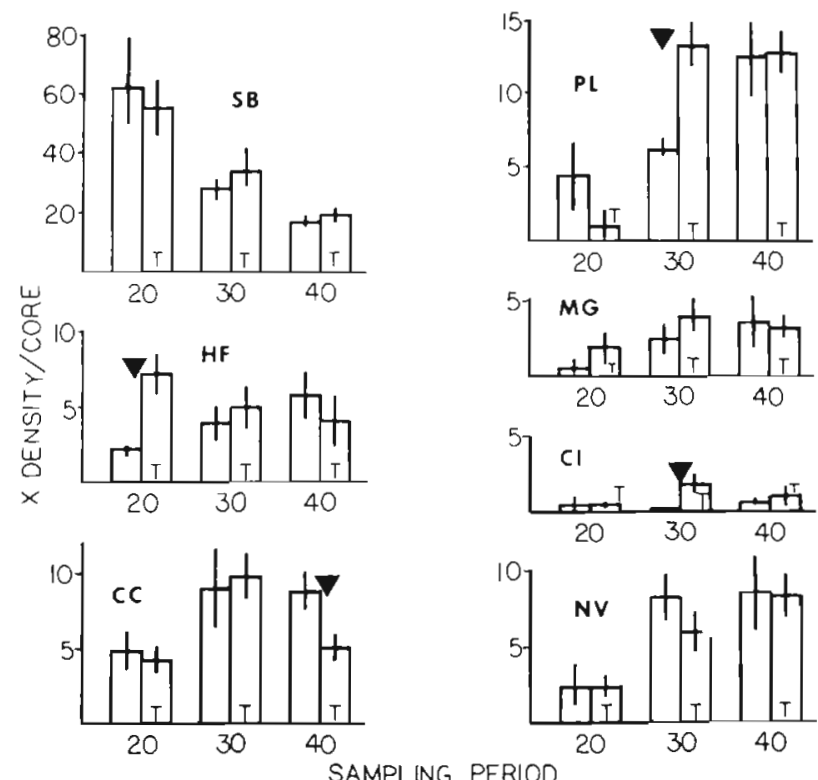

Fig. 8. Mean abundances ( $\pm 1 \mathrm{SE}$ ) of macrofaunal recruit-
ment into cores with $(\mathrm{T})$ and without artificial tubes. Downward arrowheads: significant differences $(p<0.05)$ between abundances in tube treatment and short-term control cores

and the non-polychaete fauna (Table 3). Why these species responded differently is unclear. They do comprise a group of seasonally abundant species whose population increases in the Cove are very localized relative to the more consistently present species (Zajac and Whitlatch, 1982a, b). Their temporally and spatially variable settlement patterns may tend to obscure any statistical detection of inhibition and/or facilitation, or their presence as members of the community may be too short for biotic interactions to occur. Lastly, the 2 amphipods tend to recruit initially into the cores as adults, rather than juveniles (own obs.), and may escape intense biotic interactions with the resident polychaetes.

The finding of inhibitory interactions among established infauna and subsequent infaunal colonizers in Alewife Cove is consistent with prevailing views of the importance of adult-larval and adult-juvenile interactions influencing the structure of soft-substrate communities (Woodin, 1976; Peterson, 1979) and conforms reasonably well to the inhibition model developed by Connell and Slatyer (1977). In addition, these results support our earlier suggestion (Zajac and Whitlatch, 1982b) that Polydora ligni and Streblospio benedicti inhibited the establishment of Capitella capitata in disturbed experimental buckets for up to $400 \mathrm{~d}$ in an area usually dominated by $C$. capitata. While we presently have no direct evidence of what types of specific mechanisms led to the interactions observed in our study, we feel that the nature of intraspecific larval settling behavior of the manipulated species may pro- 
vide one possible explanation. Table 3 indicates that larvae and juveniles of manipulated species preferentially settled or had increased survivorship near conspecifics. Gregarious settling behavior apparently was not always the result of larvae responding to smallscale alterations in the local hydrodynamic regime caused by the presence of tubes (Eckman, 1979). Our data comparing settling patterns of species in cores containing simulated tubes with cores containing no artificial tubes showed no consistent pattern. Other factors such as species-specific modification of the sediment surface or exudate production may stimulate larvae to settle near the presence of conspecifics although to what extent remains conjectural. A simpler explanation relates to the reproductive behavior of the manipulated species. All display some form of brood protection and a reduced planktonic larval phase (Table 1). As Grassle and Grassle (1974) noted, brooding may permit larvae to settle almost immediately upon release from the adult. The resultant effect is the ability of brooding species to achieve rapid and localized increases in population densities and preempt space within the habitat. Through sheer abundance, therefore, the tentaculate surface-feeding polychaetes may inhibit settling of other species and arrest the successional process. Dense assemblages of tubiculous polychaetes are fairly common, especially in estuarine habitats (e.g. Sanders et al., 1965; Boesch, 1973, 1977; Watling, 1975; Zajac and Whitlatch, 1982a; Levin, 1984). Thus, this type of inhibitory interaction may be a common aspect of ambient and successional dynamics in these habitats.

Comparing our results to those from a similar study conducted by Gallagher et al. (1983) reveals both interesting similarities and differences. Working on an intertidal sand flat near the Skagit River, Washington, USA, they manipulated the abundances of several species of infauna in cores planted in the sediment. As in our study, Skagit flat infaunal community development could not always be described by a single Connell-Slatyer successional model. In contrast, however, they found facilitation to be the predominant biotic interaction during succession as several of the manipulated species (notably Hobsonia florida and the tubedwelling tanaid amphipod Tanais sp.) enhanced the settlement of larval and juvenile members of the infaunal community. Inhibition was seen only twice during their study: once when $H$. florida reduced the recruitment of an oligochaete and once when Tanais sp. recruitment was inhibited by the presence of the deposit-feeding bivalve Macoma balthica.

Several factors (e.g. types and densities of organisms manipulated, habitat differences, and/or differences in experimental design) may explain the differences in the outcome of the 2 studies. Gallagher et al. (1983) argue that facilitation on the Skagit flat was the result of preferential settlement around tube builders due to 'small-scale alterations in the environment, caused either by the tube or feeding activities of the deposit feeders'. We argue here that inhibitive interactions among the polychaete infauna of Alewife Cove were the result of space preemption due to intraspecific gregarious settlement of the manipulated species which have no, or limited, larval dispersal. This difference may have been due to the densities at which experimental species were added to the cores and their subsequent population fluctuations. For example, in our study initial densities of Hobsonia florida were 4 and 8 indiv. $9.08 \mathrm{~cm}^{-2}$ core and reached densities exceeding 40 indiv. core ${ }^{-1}$ (Fig. 2). In contrast, Gallagher et al. (1983) seeded their experimental cores with 2,4 , or $6 \mathrm{H}$. florida $10 \mathrm{~cm}^{-2}$ core, and densities remained relatively low during the course of their experiments. The starting and subsequent densities of $S$. benedicti and P. ligni in our study were also relatively higher than densities of the other species manipulated by Gallagher et al. (1983). If facilitation and inhibition are density-dependent processes, then these density differences in initial conditions, and population fluctuations during the experiments, may explain our contrasting results. At low densities, facilitation may predominate as colonists respond to 'positive' habitat alterations (e.g. beneficial changes in sediment mobility and chemistry, microbial activity; Gallagher et al., 1983) caused by the already present tubiculous infauna with little, or no negative affects due to their presence. However, as densities increase, the attractiveness of the habitat modified by tube builders may be overwhelmed by negative aspects such as space preemption, food resource depletion (Thistle, 1981), and behavioral interactions which interfere with settlement and/or feeding (Levin, 1982, 1984); and subsequent colonizers are inhibited from settling or experience increased juvenile mortality. Thus, when initial colonization occurs at low densities and the species involved do(es) not exhibit high rates of population growth, facilitation and/or tolerance may be the prevailing types of interspecific interactions influencing infaunal successional dynamics. In contrast, when initial colonizers attain high densities, as in our study, inhibitive interactions may prevail. Our results do suggest that when initial densities were low, facilitation and tolerance occurred (Table 3), but as densities increased, inhibition became more common.

In addition to density, biotic interactions are likely to be affected by the types of infauna present in the disturbed habitat and the types colonizing into the habitat. This was apparent in Alewife Cove, as the polychaetes exhibited primarily inhibition, whereas their effects on the two amphipods and the anthozoan 
were not significant (tolerance) or usually facilitative (Table 3). This may be due to more similar habitat/ resource requirements between the polychaetes relative to the non-polychaete infauna.

Another factor which may influence what kinds of biotic interactions occur during infaunal succession and promote the differences noted above relates to habitat hydrodynamic characteristics. On the Skagit flat, Gallagher et al. (1983) found the presence of simulated tubes (wooden applicator sticks) enhanced the rate of settlement of several infaunal species. Their finding was consistent with earlier studies by Eckman (1979) on the Skagit flat which also demonstrated the importance of small structures causing local aggregations of some infaunal species apparently related to small-scale alterations in hydrodynamic flow above the sediment-water interface. However, Gallagher et al. (1983) suggest that this mechanism was probably not the basis of the facilitation they observed but rather 'active habitat selection by the larvae and juveniles of the Skagit community' since the densities and spacing of the artificial tubes they used should have led to 'enhanced overall rates of boundary shear stress' and larvae and juveniles 'would be unlikely to accumulate selectively' in their experiments.

In contrast to the Skagit flat where tidal flow reaches speeds of 10 to $30 \mathrm{~cm} \mathrm{~s}^{-1}$ (Eckman, 1979), the upper portions of Alewife Cove are characterized by relatively low tidal flow conditions ( 1 to $2 \mathrm{~cm} \mathrm{~s}^{-1}$ ). The effect of reduced flow in Alewife Cove may explain why the simulated tubes had limited effect on infaunal recruitment patterns via local accumulation as found by Eckman (1979). It is important to point out that in our study tube controls were in buckets approximately $15 \mathrm{~cm}$ above the sediment-water interface due to the PVC frame. Under these conditions any flow effects around tubes may have been overshadowed by flow differences around the PVC frame, rendering the tube experiments equivocal. However, due to the low flow conditions and arguments presented in Materials and Methods, we feel these experiments give some insight into the effects of tubes in the ambient sediments. Also, recruitment into tube controls was usually not significantly different from short-term controls, suggesting that any positive or negative interactions were due to the presence of the tube builders and not just the tubes themselves. Under reduced flow conditions, larvae with limited dispersal may have a greater probability of settling back into the parental population increasing local densities which can subsequently inhibit the settlement of other colonizers. With increasing flow, tubes may selectively accumulate infauna (Eckman, 1979), or the flow may disperse larvae produced by initial colonizers and keep densities below levels at which inhibition occurs enabling colonists to utilize micro- habitats generated by previously settled tube builders We suggest that the magnitude of near-bottom water flow may determine to some extent specific mechanisms responsible for early stage infaunal successional dynamics (Zajac and Whitlatch, in prep.).

In relation to prevailing theories of marine softbottom succession, our results can be interpreted in several ways depending on how the infaunal successional process is perceived. The more traditional view is that following a perturbation a series of successional states occur, beginning with an 'opportunistic' assemblage of organisms and culminating in a 'climax' community composed of long-lived species with K-type life-history traits (see Pearson and Rosenberg, 1978; Rhoads et al., 1978, for further discussion). This formulation, while drawing heavily from studies of terrestrial plant communities (e.g. Odum, 1969), appears appropriate for certain types of soft-bottom environments (e.g. McCall, 1977; Rhoads et al., 1978). Since the species we manipulated are typical examples of opportunistic forms and we examined successional dynamics for a relatively short time, our findings appear to focus primarily upon biological interactions among a group of early successional stage colonists. We were, therefore, unable to test fully whether differential competitive ability exists among various successional groups of species and our tests of the Connell-Slatyer models remain incomplete. Our results do demonstrate, however, that while opportunistic species are generally considered to be poor competitors, each manipulated species was capable of reducing the abundance of other opportunistic species for periods up to $40 \mathrm{~d}$ and inhibitory interactions can be important during initial stages of infaunal succession. Although this seems a short time period, it is sufficient for each species to complete a life cycle (Table 1). It appears that assessing the competitive abilities of early (short-lived) and late (long-lived) colonists in benthic habitats is somewhat arbitrary and must be scaled to an individual's life history

An alternative view to infaunal succession is based on our previous argument (Zajac and Whitlatch, 1982b) which viewed one community's successional ceiling as another community's successional floor. For example, species which behave opportunistically in deeper water habitats are often dominant and persistent (e.g. climax) members of shallow-water estuaries and embayments (e.g. Watling, 1975; Santos and Simon, 1980b; Zajac and Whitlatch, 1982a; Santos and Bloom, 1983; Levin, 1984). Alewife Cove infaunal community dynamics have been studied for more than 8 yr (Welsh et al., 1978; Welsh and Whitlatch, 1980; Zajac and Whitlatch, 1982a, b, this study) and data suggest a general long-term consistency in species composition and temporal/spatial population fluctuations. Boesch 
et al. (1976) also noted that estuarine communities display 'high stability in their resistance to, and resilience from, disturbance'. For these types of communities the traditional view of succession may not be appropriate and our results should be interpreted in a different manner. When considered in the context of prevailing community dynamics in Alewife Cove (Zajac and Whitlatch 1982a, b), the biotic interactions described in the present study apply not just to the initial stages of succession, but rather to the whole successional process. The process can best be described by a conceptual model presented by Johnson (1973) in which the community is a temporal mosaic 'continually varying in response to a history of disturbance ... and therefore [is] at different levels of succession' and a more formal construction given by Caswell (1978) in which the community is comprised of habitats (cells) which are continually disturbed and recolonized by the fauna.

We envisage the estuarine infaunal successional process as being incredibly dynamic as a consequence of being exposed to continual abiotic and biotic perturbation. Species inhabiting these systems are well adapted to disturbance phenomena and they possess life histories which allow them to exploit disturbed patches of habitat and attain very dense populations. The specific form of the successional process is dependent upon the nature and abundance of potential colonists and the timing of disturbance relative to seasonal infaunal population dynamics. When inhibitory interactions occur, one of several species may locally dominate as strongly hierarchical competitive interactions appear not to exist among many of the colonizing species (Table 3 ). Species dominance patterns most likely are determined by which species finds the disturbed habitat first and successfully preempts the spatial resource. Following population expansion, these species may destroy their habitat (e.g. through food depletion, sediment destabilization) or are, themselves, disturbed (e.g. by predation, sediment erosion, anoxic events), resulting in a localized population decline and re-invasion of the habitat by other species. As shown by our data (Fig. 1 to 7 ), these cycles can occur over relatively small temporal scales (weeks).

In summary, shallow-water estuarine infaunal colonizers can delay the successional process, and contrary to the Gallagher et al. (1983) contention that 'softbottom benthic succession can be explained by the facilitation model', inhibitory interactions appear to be of primary importance in these types of soft-bottom communities. Santos and Bloom (1983) also found no supporting evidence based on community classification analyses for facilitation in a shallow habitat in Tampa Bay, Florida, and suggested that inhibition may be operating in this infaunal community.
The balance between whether inhibition or facilitation predominates during succession may depend on habitat conditions, such as water flow, the species involved and the densities they attain, and periodicities of infaunal reproduction. The tolerance model, at this time, appears to be enigmatic. Both we and Gallagher et al. (1983) defined tolerance similarly (little or no effect in this study; species neither facilitated or inhibited in theirs) and found examples of this type of (or lack of) interaction. Though conceivably important, its identification may prove difficult unless further, more well established criteria, are used to define tolerance (see Gallagher et al., 1983 for examples). While a variety of biotic interactions are important during various phases of infaunal succession, we see the next important steps as (a) establishing their importance in different types of soft-bottom habitats and (b) elucidating the mechanism(s) controlling them.

Acknowledgements. We thank B. Lussier, V Starczak and J. Weinberg for helping with deployment of the experiment and processing of samples. J. Lorensen, S. Butler and R. DeGoursey assisted in manuscript preparation. The manuscript was greatly improved by comments from 3 anonymous reviewers. This research was supported by NSF grant OCE 80-18447 and is Contribution Number 170 of the Marine Sciences Institute, The University of Connecticut.

\section{LITERATURE CITED}

Arntz, W. E., Rumohr, H. (1982). An experimental study of macrobenthic colonization and the importance of seasonal variation in temperate latitudes. J. exp. mar. Biol. Ecol. 64 . $17-45$

Boesch, D. F. (1973). Classification and community structure of macrobenthos in the Hampton Rhoads area, Virginia. Mar. Biol. 21: 226-244

Boesch, D. F. (1977). A new look at the zonation of benthos along the estuarine gradient. In: Coull, B. C. (ed.) Ecology of the marine benthos. University of South Carolina Press, Columbia, p. 245-266

Boesch, D. F., Wass, M. L., Virnstein, R. W. (1976). The dynamics of estuarine benthic communities. In: Wiley, $M$ (ed.) Estuarine processes. Academic Press, New York p. 177-196

Cammen, L. M. (1979). The macro-infauna of a North Carolina salt marsh. Am. Mid. Nat. 102: 244-253

Caswell, H. (1978). Predator-mediated coexistence: a nonequilibrium model. Am. Nat. 112: 127-154

Connell, J. H, Slatyer, R. O. (1977). Mechanisms of succession in natural communities and their role in community stability and organization. Am. Nat. 111: 1119-1144

Dauer, D. M, Simon, J. L. (1976). Habitat expansion among polychaetous annelids repopulating a defaunated marine habitat. Mar. Biol. 37: 169-177

Eckman, J. E. (1979). Small-scale patterns and processes in a soft-substratum, intertidal community. J. mar. Res. 37 $437-457$

Eckman, J. E., Nowell, A. R. M., Jumars, P. A (1981). Sediment destabilization by animal tubes. J. mar. Res. 39: 361-374

Gallagher, E. D., Jumars, P. A., Trueblood, D. D. (1983) 
Facilitation of soft-bottom benthic succession by tube builders. Ecology 64: 1200--1216

Grassle, J. F., Grassle, J. P. (1974). Opportunistic life histories and genetic systems in marine benthic polychaetes. $\mathrm{J}$. mar. Res. 32: 253-284

Grassle, J. F., Grassle, J. P. (1977). Temporal adaptations in sibling species of Capitella. In: Coull, B. C. (ed.) Ecology of the marine benthos. University of South Carolina Press, Columbia, p. $177-190$

Herring, J. P. R. (1978). The effects of a srnall estuary on the processing of freshwater runoff and tidal water. Master's thesis, The University of Connecticut

Johnson, R. G. (1973). Conceptual models of benthic communities. In: Schopf, T. J. M. (ed.) Models in paleobiology. Freeman Cooper and Co., San Francisco, p. 148-159

Levin, L. A. (1982). Interference interactions among tubebuilding polychaetes in a dense infaunal assemblage. $\mathrm{J}$. exp. Mar. Biol. Ecol. 65: 107-119

Levin, L. A. (1984). Life history and dispersal patterns in a dense infaunal polychaete assemblage: community structure and response to disturbance. Ecology 65: 1185-1200

Levinton, J. S., Stewart, S. (1982). Marine succession: the effect of two deposit-feeding gastropod species on the population growth of Paranais litoralis Muller 1784 (Oligochaeta). J. exp. mar. Biol. Ecol. 59: 231-241

McCall, P. L. (1977). Community patterns and adaptive strategies of the infaunal benthos of Long Island Sound. J. mar. Res. 35: 221-266

McCall, P. L. (1978). Spatial-temporal distributions of Long Island Sound infauna: the role of bottom disturbance in a nearshore habitat. In: Wiley, M. L. (ed.) Estuarine interactions. Academic Press, New York, p. 191-219

Mills, E. L. (1967). The biology of an ampeliscid amphipod crustacean sibling species pair. J. Fish. Res. Bd Can. 24: 305-355

Odum, E. P. (1969). The strategy of ecosystem development. Science 164: 262-270

Pearson, T. H., Rosenberg, R. (1978). Macrobenthic succession in relation to organic enrichment and pollution of the marine environment. Oceanogr. mar. Biol. A. Rev. 16: 229-311

Paine, R. T., Levin, S. A. (1981). Intertidal landscapes: disturbances and the dynamics of pattern. Ecol. Monogr. 51 $145-170$

Peterson, C. H. (1979). Predation, competitive exclusion, and diversity in the soft-sediment benthic communities of estuaries and lagoons. In: Livingstone, R. J. (ed.) Ecological processes in coastal and marine systems. Plenum Press, New York, p. 233-264

Rhoads, D. C., McCall, P. L., Yingst, J. Y. (1978). Disturbance and production on the estuarine seafloor. Am. Sci. 66: $557-586$

Rhoads, D. C., Boyer, L. F. (1982). The effects of marine benthos on physical properties of sediments: a successional perspective. In: McCall, P. L., Tevesz, M. J. S. (ed.) Animal-sediment relations. Plenum Publishing, New York, p. 3-52
Richter, W., Sarnthien, M. (1977). Molluscan colonization of different sediments on submerged platforms in the western Baltic Sea. In: Keegan, B. F., Ceidigh, P. O., Boaden, P. J. S. (ed.) Biology of benthic organisms. Pergamon Press, New York, p. 531-539

Sanders, H. L., Mangelsdorf, P. C., Hampson, G. R. (1965). Salinity and faunal distribution in the Pocasett River, Massachusetts. Limnol. Oceanog. 10: R216-R229

Santos, S. L., Bloom, S. A. (1983). Evaluation of succession in an estuarine macrobenthic soft-bottom community near Tampa, Florida. Int. Revue ges. Hydrobiol. 68: 617-632

Santos, S. L., Simon, J. L. (1974). Distribution and abundance of the polychaetous annelids in a south Florida estuary. Bull. mar. Sci. 24: 669-689

Santos, S. L., Simon, J. L. (1980a). Marine soft-bottom community establishment following annual defaunation: larval or adult recruitment? Mar. Ecol. Prog. Ser. 2: 235-241

Santos, S. L., Simon, J. L. (1980b). Response of a soft-bottom benthos to annual catastrophic disturbance in a south Florida estuary. Mar. Ecol. Prog. Ser. 3: 347-355

SAS (1982). SAS user's guide: statistics. SAS Institute Incorporated, Cary, North Carolina

Simon, J. L., Dauer, D. M. (1977). Reestablishment of a benthic community following natural defaunation. In: Coull, B. C. (ed.) Ecology of the marine benthos. University of South Carolina Press, Columbia, p. 139-154

Thistle, D. (1981). Natural physical disturbances and communities of marine soft bottoms. Mar. Ecol. Prog. Ser. 6: 223-228

Walting, L. (1975). Analysis of structural variations in a shallow estuarine deposit feeding community. J. exp. mar. Biol. Ecol. 19: 275-313

Welsh, B. L., Herring, J. P., Read, L. M. (1978). The effects of reduced wetlands and storage basins on the stability of a small Connecticut estuary. In: Wiley, M. L. (ed.) Estuarine interactions. Academic Press, New York, p. 381-401

Welsh, B. L., Whitlatch, R. B. (1980). A study of Alewife Cove: its siltation, eutrophication and hydraulic character. Report of the Commissioner, Department of Environmental Protection, State of Connecticut

Wilson, W. H. (1983). The role of density dependence in a marine infaunal community. Ecology 64: 295-306

Woodin, S. A. (1976). Adult-larval interactions in dense infaunal assemblages: patterns of abundance. J. mar. Res. 34: $24-41$

Woodin, S. A. (1981). Disturbance and community structure in a shallow water sand flat. Ecology 62: 1052-1066

Zajac, R. N. (1981). Successional and ambient infaunal community dynamics in a New England estuary. Master's thesis, The University of Connecticut

Zajac, R. N., Whitlatch, R. B. (1982a). Responses of estuarine infauna to disturbance. I. Spatial and temporal variation of recolonization. Mar. Ecol. Prog. Ser. 10: 1-14

Zajac, R. N., Whitlatch, R. B. (1982b). Responses of estuarine infauna to disturbance. II. Spatial and temporal variation of succession. Mar. Ecol. Prog. Ser. 10: 15-27 